\title{
HUBUNGAN ANTARA TINGKAT STRES DENGAN KUALITAS TIDUR PADA WARGA BINAAN DI LEMBAGA PEMASYARAKATAN KLAS IIA YOGYAKARTA
}

\section{THE CORRELATION BETWEEN STRESS LEVELS AND SLEEP QUALITY ASSISTED PEOPLE IN WOMAN PENITENTIARY OF CLASS IIA YOGYAKARTA}

\author{
Dheska Arthyka Palifiana ${ }^{1}$, Ratih Kumoro Jati ${ }^{2}$
}

\begin{abstract}
${ }^{* 1}$ Program Studi Kebidanan (D4) Universitas Respati Yogyakarta, Jl.Laksda Adisucipto Km 6.3 Depok, Sleman,Yogyakarta. Telp. (0274) 489780. Email: dheska87@gmail.com, Indonesia.

2 Program Studi Kebidanan (D3) Fakultas Kesehatan, Universitas Jenderal Achmad Yani Yogyakarta, Kampus II, Jl. Brawijaya Ring Road Barat, Ambarketawang, Gamping, Sleman, Yogyakarta. Telp. (0274) 4342000, Indonesia.
\end{abstract}

\begin{abstract}
Background: To have rest or to sleep is basic need that needed by everyone. To have enough rest or sleep will make body functioned optimally. By sleeping people can restore or to rest the physical after whole day activities, it can reduce stress and anxiety. It also improve concentration and improve ability when doing daily activities. Factors that affect quality and quantity of sleep include ill, fatigue, environment, lifestyle, emotional stress, diet, smoking, stimulant, alcohol, and motivation. The stress level on assisted citizen of woman's prisoner will be more severe than who are not in prison so as stress can be overcome then the quality of sleep becomes better.

Objective:To know the correlation between stress levels and sleep quality on assisted people in woman Penitentiary class II A Yogyakarta.

Methods: The research was conducted at women's prison class II A Yogyakarta. Research population was 117 women prisoners. The sample was 50 women prisoners. Type of the research was descriptive analytic research with cross sectional design. Statistical analysis used chi square. The sampling technique used purposive sampling.

Results: The stress level was mostly in high category as many as 17 respondents experienced stress (34\%). Sleep quality of the respondents were mostly in bad category as many as 38 respondents (76\%). There is a correlation between stress level and sleep quality on women prisoners in Penitentiary class II A Yogyakarta with $p$-value (0.033).

Conclusion: There is a correlation between stress level and sleep quality on women prisoners in Penitentiary class II A Yogyakarta.
\end{abstract}

Keywords:S tress level, sleep quality, assisted people, penitentiary

\section{PENDAHULUAN}

Lembaga Pemasyarakatan (LAPAS) merupakan tempat narapidana menjalani hukuman berdasarkan keputusan pengadilan dan merupakan tempat yang penuh dengan tekanan. Istilah lapas/penjara sudah menyebabkan perasaan takut dan stigma yang tidak menyenangkan bagi penghuninya. Lapas dapat menjadi pemicu terjadinya tingkat kecemasan dan stress pada narapidana. ${ }^{1}$ Masuk lembaga pemasyaraatan dan menjalani kehidupan sebagai narapidana adalah suatu stress yang tidak diinginkan, stress yang berat dan membutuhkan penyesuaian diri yang berat.

Penyesuaian tersebut meliputi fisik, psikis dan sosial. Situasi lingkungan yang terpaksa harus didapat, dibedakan atas lingkungan fisik maupun sosial. Lingkungan fisik adalah semua benda mati yang ada di sekeliling narapidana, misalnya ruangan sel, bangunan penjara dan pagar penjara. 
Sedangkan lingkungan sosial terdiri dari teman satu sel, sipir, tukang kebun, tim medis penjara, juru masak dan rohaniawan. ${ }^{2}$

Kecemasan yang dialami oleh narapidana wanita berasal dari faktor yang sangat beragam dan subyektif. Walaupun narapidana pria dan wanita memiliki pengalaman yang sama dalam penjara, namun banyak ditemukan argumentasu bahwa narapidana wanita lebih mungkin mengalami penyakit mental akibat tekanan terkait dengan memelihara keluarga agar tetap utuh, peran sebagai orang tua yang harus mengurus anak-anak dan kebutuhan untuk berhubungan dengan konflik perkawinan atau hubungan yang belum terpecahkan, semua itu menjadi terbatas ketika mereka berada dalam penjara. ${ }^{3}$

Stress adalah ketidakmampuan mengatasi ancaman yang dihadapi oleh mental, fisik, emosional dan spriritual yang pada suatu saat dapat mempengaruhi kesehatan fisik manusia tersebut. Stress normal merupakan reaksi alamiah yang berguna, karena stress akan mendorong kemampuan seseornag untuk mengatasi kesulitan kehidupan. Tekanan stres yang besar hingga melampaui daya tahan individu, maka akan menimbulkan gejala-gejala seperti sakit kepala, mudah marah dan kesulitan untuk tidur. ${ }^{4}$

Tidur merupakan proses penting bagi manusia karena terjadi suatu proses pemulihan tubuh. Kualitas tidur ditentukan dengan bagaimana seseorang dapat mempersiapkan pola tidurnya di malam hari seperti kedalaman tidur, kemampuan tidur dan kemudahan untuk tidur. ${ }^{5}$ Stress dan tidur mempunyai hubungan yang erta, kualitas tidur yang buruk dapat dikaitkan dengan kesehatan mental seperti stress. ${ }^{6}$

Kebutuhan tidur sesuai usia yaitu usia 0-1 bulan membuthukan tidur 14-18 jam setiap hari, usia 1-18 bulan membutuhkan waktu tidur 12-14 jam setiap hari termasuk tidur siang, usia 3-6 tahun membutuhkan waktu untuk tidur 11-13 jam termasuk tidur siang, usia 6-12 tahun membuthkan waktu tidur 10 jam, usia 12 - 18 tahun kebutuhan tidur yang sehat adalah 8-9 jam, usia $18-40$ tahun membutuhkan waktu tidur 7-8 jam dan lansia cukup tidur 7 jam perhari. $^{7}$

Ancaman akibat kurang tidur yaitu hilang konsentrasi saat melakukan kegiatan, memperburuk kondisi kesehatan tubuh, kulit telihat lebih tua, hilang fokus saat berkendara, munculnya obesitas, stress yang meningkat, sering lupa. Pola tidur yang baik adalah 6-7 jam tidur malam untuk orang dewasa. $^{7}$

Faktor-faktor yang mempengaruhi tidur diantaranya adalah penyakit, latihan dan kelelahan, stress psikologis, obat, nutrisi, lingkungan. ${ }^{8}$ Banyaknya tekanan yang dialami oleh warga binaan (narapidana) wanita di lapas perempuan seringkali menyebabkan kesulitan untuk tidur, berdasarkan wawancara dengan warga binaan di lapas perempuan KLAS IIA Yogyakarta menyatakan bahwa mereka 
seringkali tidak dapat tidur di malam hari maupun dimalam hari dikarenakan memikirkan nasib keluarga dan juga masa depannya kelak.

\section{BAHAN DAN CARA PE NELITIAN}

Penelitian ini adalah penelitian kuantitatif dengan jenis penelitian deskriptif analitik dan design penelitian Cross Sectional. Populasi dalam penelitian ini adalah semua narapidana wanita di LAPAS KLAS IIA Yogyakarta sejumlah 117 responden. Sampel diambil dengan teknikPurposive Sampling sebanyak 50 responden .

Instrumen yang digunakan pada penelitian ini berupa kuesioner yang terdiri dari 2 kuisioner yaitu kuisioner untuk mengukur tingkat stress menggunakan Depression Anxiety Stress Scale42 (DASS 42) yang terdiri dari 42 item pertanyaan dengan masing-masing 14 skala depresi, 14 skala kecemasan dan 14 skala untuk stress. sedangkan untuk mengukur kualitas tidur menggunakan The Pittsburgh Sleep Qulity Index (PSQI) yang terdiri dari 19 pertanyaan dan 5 pertanyaan untuk teman sekamar.

Data hasil penelitian dianalisis dengan metode univariat dan bivariat menggunakan analisis Chi Square.

\section{HASIL DAN PEMBAHASAN}

Tabel 1 Tingkat Stress Responden

\begin{tabular}{ccc}
\hline Tingkat Stress & $\mathbf{f}$ & $\%$ \\
\hline Normal & 13 & 26,0 \\
Ringan & 8 & 16,0 \\
Sedang & 6 & 12,0 \\
berat & 6 & 12,0 \\
sangat berat & 17 & 34,0 \\
\hline Jumlah & 50 & 100 \\
\hline
\end{tabular}

Berdasarkan Tabel 1 dapat diketahui bahwa diketahui bahwa sebagian besar tingkat stress responden dalam kategori sangat berat sebanyak 17 responden $(34,0 \%)$, kategori normal atau tidak stress sebanyak 13 responden $(26,0 \%)$, stress ringan sebanyak 8 responden (16,0\%), stres sedang dan berat masing-masing 6 responden $(12,0 \%)$.

Stress adalah respon tubuh tidak spesifik terhadap kebutuhan tubuh yang terganggu. Stress merupakan suatu fenomena universal yang terjadi dalam kehidupan sehari-hari dan tidak dapat dihindari dan akan dialami oleh setiap orang. Stress memberikan dampak secara total pada individu seperti dampak fisik, sosial, intelektual, psikologis dan spriritual. ${ }^{9}$

Tabel 2. Kualitas Tidur Responden

\begin{tabular}{ccc}
\hline Kualitas Tidur & f & $\%$ \\
\hline Baik & 12 & 24,0 \\
Buruk & 38 & 76,0 \\
\hline Jumlah & 50 & 100 \\
\hline
\end{tabular}

Berdasarkan tabel 2 diketahui bahwa sebagian besar kualitas tidur responden dalam kategori buruk sebanyak 38 responden $(76,0 \%)$, dan kualitas tidur yang baik dialami oleh 12 responden (24,0\%). 


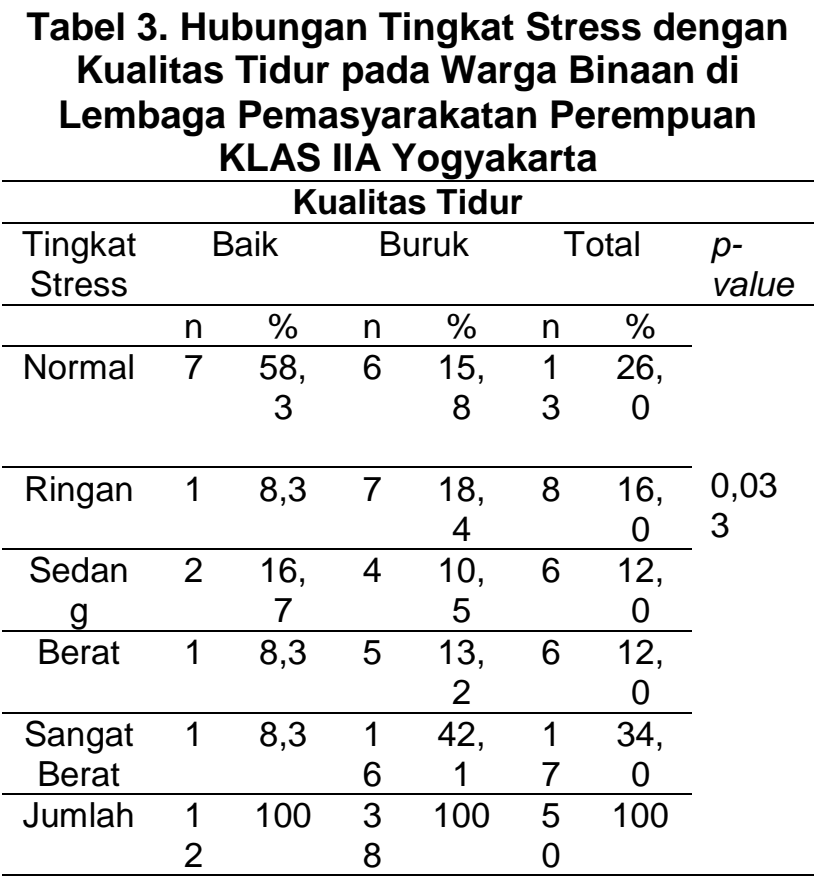

Berdasarkan tabel 3 diketahui sebagian besar tingkat stress responden dalam kategori sangat berat dengan kualitas tidur buruk sebanyak 16 orang $(42,1 \%)$ dan tingkat stress dalam kategori normal dengan kualitas tidur baik sebanyak 7 orang $(58,3 \%)$. Hasil uji statistik dengan menggunakan uji Chi Square diketahui nilai $p$-value sebesar 0,033 dimana nilai tersebut lebih kecil dari nilai $=0,05$ yang berarti ada hubungan antara tingkat stress dengan kualitas tidur pada warga binaan di Lembaga Pemasyarakatan Perempuan KLAS IIA Yogyakarta.

Hasil analisis data penelitian diketahui sebagian besar tingkat stress reponden dalam kategori sangat berat sebanyak 17 responden $(34,0 \%)$, normal sebanyak 13 responden $(26,0 \%)$, stress ringan sebanyak 8 responden $(16,0 \%)$, stress sedang dan berat masing-masing sebanyak 6 responden
$(12,0 \%)$. Kondisi stress adalah suatu bentuk tanggapan seseorang, baik fisik maupun mental terhadap suatu perubahan di lingkungan yang dirasakan mengganggu dan mengakibatkan dirinya terancam. ${ }^{10}$

Selama berada di Lembaga Pemasyarakatan, ruang gerak narapidana dibatasi dan mereka terisolasi dari masyarakat. Keadaan seperti ini dapat menjadi stressor yang menyebabkan stress pada narapidana. Stress yang diradakan oleh individu yang menimbulkan upaya untuk melakukan reaksi terhadap stress yang dialaminya. Reaksi tersebut merupakan suatu aktivitas untuk melakukan penyesuaian diri terhadap situasi perangsang tertentu, yang apabila tidak dapat dilakukan dengan baik akan menyebabkan gangguan fisik maupun kejiwaan. ${ }^{11}$

Hasil analisis data penelitian diketahui kualitas tidur responden sebagian besar dalam kategori buruk sebanyak 38 responden $(76,0 \%)$ sedangkan responden yang mempunyai kualitas tidur baik sebanyak 12 responden $(24,0 \%)$. Tidur merupakan hal yang sangat penting bagi manusia, karena terjadi suatu proses pemulihan serta penting untuk keseimbangan fisiologis dan fungsi mental dalam jangka pendek maupun jangka panjang. Kualitas tidur yang cukup adekuat sangat penting bagi tubuh salah satunya adalah sebagai fungsi normal metabolik dan proses hormonal. ${ }^{6}$ salah satu faktor yang mempengaruhi kualitas tidur adalah stress dan kecemasan. 
Berdasarkan hasil penelitian diketahui bahwa responden yang tingkat stressnya dalam kategori sangat berat mempunyai kualitas tidur yang buruk sebanyak 16 responden $(42,1 \% 0$ sedangkan responden yang tingkat stressnya dalam kategori normal mempunyai kualitas tidur yang baik sebanyak 7 responden (58,3\%). Hasil analisis data menggunakan analisis chi square diperoleh p-value $0,033<0,005$ yang berarti ada hubungan antara tingkat stress dengan kualitas tidur pada warga binaan di Lembaga Pemasyarakatan Perempuan KLAS IIA Yogyakarta.

Lembaga pemasyarakatan (lapas) atau yang lebih dikenal dengan nama penjara. Istilah tersebut sudah sangat membuat rasa takut dan perasaan yang tidak menyenangkan, karena stigma yang melekat didalamnya, seperti pemukulan, penyiksaan, pelecehan seksual, kesehatan yang buruk, fasilitas yang minim dan kapasitas yang berlebihan. Secara umum, permasalahan yang menuntut narapidana untuk menyesuaikan diri adalah kehilangan kebebasan fisik, kehilangan kontrol atas hidup, kehilangan keluarga, kehilangan barang dan jasa, kehilangan keamanan, kehilangan hubungan heteroseksual, kurangnya stimulasi dan gangguan psikologis. Semua tekanan yang dialami narapidan di dalam penjara dapar menimbulkan penyakit, baik itu penyakit fisik maupun psikis, seperti sering melamun, mudah tersinggung, menyerang orang lain dan bahkan bunuh diri. ${ }^{7}$

Seseorang yang mempunyai kualitas tidur buruk adalah yang mempunyai masalah kesehatn fisik dan psikologis. ${ }^{12}$ Stress emosional dan akademik mempunyai dampak negatif terhadap tidur.

\section{KESIMPULAN}

Berdasarkan hasil penelitian yang telah dilakukan dapat disimpulkan tingkat stress yang dialami oleh warga binaan di LAPAS sebagian besar dalam kategori sangat berat, kualitas tidur sebagian besar dalam kategori buruk, dan ada hubungan antara tingkat stress dengan kualitas tidur pada warga binaan di Lembaga Pemasyarakatan Perempuan KLAS IIA Yogyakarta. Berdasarkan hasil penelitian yang diperolehLembaga Pemasyarakatan Perempuan KLAS IIA Yogyakarta diharapkan lebih meningkatkan kegiatan kerohanian, kebugaran, sosial untuk para warga binaan agar menurunkan tingkat stress yang dialami sehingga akan meningkatkan kualitas tidur para warga binaan. Bagi Institusi Pendidikan diharapkan menjalin kerjasama secara rutin dengan pihak lapas untuk memberikan penyuluhan demi meningkatkan kualitas hidup para warga binaan.Bagi Peneliti selanjutnyadapatmelakukanpenelitian yang sejenis dengan melihat aspek yang lain yang dapat mempengaruhi terjadinya stress sehingga dapat diatasi untuk meningkatkan kualitas tidur para warga binaan. 


\section{TERIMA KASIH}

1. Prof. Dr. dr. Santoso, MS, Sp.Ok, Rektor Universitas Respati Yogyakarta, email: unriyo@respati.ac.id

2. Deby Zulkarnain R, M.MR, Ketua PPPM Fakultas Kesehatan Universitas Jenderal Achmad Yani Yogyakarta, 0274 4342000, email: deby.ayani142gmail.com

\section{KEPUSTAKAAN}

1. Noorsifa. Korelasi Relisiensi dengan Depresi pada Narapidana Wanita di Lembaga Pemasyarakatan KLAS IIA Banjarmasin. Yogyakarta: Universitas Gajah Mada. 2013

2. Saputra, E. Kopi. Yogyakarta: Harmoni. 2008

3. Gussak, D. Comparing the Effectiveness of Art Therapy on Depression and Locus of Control of Male and Female Inmates. The Arts In Psychotherapy. USA : Elsevier Inc. 2009

4. National Safety Counsil. Manajemen Stress. Jakarta: EGC.2004

5. Hidayat Aziz Alimul. Riset Keperawatan dan Teknik Penulisan Ilmiah. Edisi 2. Jakarta : Salemba Medika. 2007
6. Kompier, M. A., Taris, T. W., \& van Veldhoven, $\quad M$. Tossing and turning Insomnia in relation to occupational stress, rumination, fatigue, and well being. Scandinavian Journal of Work, Environment \& Health. Mei 2012. Volume: 38 (3), Hal. 238-246.

7. Departemen Kesehatan Republik Indonesia. Diperoleh dari URL: www.promkes, depkes.go.id diakses 28 Maret 2018

8. Uliyah, M. \& Hidayat, A. Azis Alimul. Keterampilan Dasar Praktik Klinik Untuk Kebidanan, Edisi 2. Jakarta Selatan : Jagakarsa. 2008

9. Rasmun. Pengertian, Stress, Sumber Stress, dan Sifat Stressor dalam: Stress, Koping dan Adaptasi. Edisi ke-1. Jakarta: Sagung Seto. 2004

10. Anoraga, P. Psikologi Kerja. Jakarta: Rineka Cipta.2001

11. Doelhadi, S. Strategi dalam Pengendalian dan Pengelolaan Stress. J urnal Sikologi Anima,. Desember 1997. Volume XII (48). Hal. 378-392

12. Lund, H. Reider, B. Whiting, A. And Prichard, R. Sleep Pattern and Predictors of Distrubed Sleep in a Large Population of College Students. Journal of Adolescence Health. Juni 2010. Volume: 48 (2), Hal. 124-132 